OPEN ACCESS

Edited by:

Sarah Till Boysen,

The Ohio State University,

United States

Reviewed by:

Alexandra Horowitz,

Columbia University, United States

*Correspondence:

Carine Savall

carine.savalli@unifesp.br

Specialty section

This article was submitted to

Comparative Psychology,

a section of the journal

Frontiers in Psychology

Received: 26 June 2020

Accepted: 11 September 2020

Published: 23 October 2020

Citation:

Savalli $C$ and Mariti $C$ (2020) Would the Dog Be a Person's Child or Best

Friend? Revisiting the Dog-Tutor

Attachment.

Front. Psychol. 11:576713

doi: 10.3389/fpsyg.2020.576713

\section{Would the Dog Be a Person's Child or Best Friend? Revisiting the Dog-Tutor Attachment}

\author{
Carine Savalli $^{1 *}$ and Chiara Mariti ${ }^{2}$ \\ ${ }^{1}$ Department of Public Politics and Public Health, Federal University of São Paulo, Santos, Brazil, ${ }^{2}$ Department of Veterinary \\ Sciences, University of Pisa, Pisa, Italy
}

Keywords: attachment, bond, caregiver, dog, friendship, tutor

Among all relationships that a human life comprises, there is often the development of interspecific relationships, especially with dogs (Julius et al., 2013). Dogs can cooperate in various scenarios, as they can guide blind people, herd sheep, rescue people, work in animal-assisted therapy, among other activities (Serpell, 2017); and beyond all operational interactions, most tutors and dogs become attached to each other (we are using the term tutor as a synonym of guardian, the one who takes care of the dog). What do people search for in an affectionate relationship with dogs? Are people searching for a new experience of caring for someone who depends on them for basic needs? For an emotional support in difficult times? For a long-term and consistent relationship, a strong connection, a mutually enjoyable contact? In other words, are people searching for a child, for a best friend or both? And how does it work from the dog's perspective? The Bowlby's theory (Bowlby, 1969) focused on child-caregiver attachment is being used to explain dog-tutor attachment. However, we argue that this approach should be integrated with the human friendship attachment theory and the intraspecific dog attachment. Therefore, it is important to revisit the approach to the dog-tutor attachment.

\section{CHILD-CAREGIVER ATTACHMENT}

The attachment bond encompasses behavioral strategies used by individuals to maximize their survival, by balancing two motivational processes: the need for protection from threats and the drive to explore the environment. A dynamic equilibrium of these two motivational processes is important for the child development (Cassidy, 2016). The attachment figure is the individual who offers comfort in stressful situations (safe haven effect) and the security to explore the surroundings (secure base effect) (Bowlby, 1969; Ainsworth et al., 1978).

In the child-caregiver attachment, two behavioral systems, namely the attachment system and the caregiving system (Julius et al., 2013), are combined to increase the chances of survival of the offspring. The attachment system is activated in children by emotional stress, triggered by internal or external stimuli, and it includes a set of behaviors used to reestablish the proximity with the caregiver such as calling, crying, etc. The caregiving system is activated in the caregiver by the 
perception of danger or by the child showing attachment behaviors. Julius et al. (2013) emphasizes that, when child and caregiver interact in synchrony and work together to maintain proximity, both systems are successfully deactivated by physical contact, such as the skin-to-skin contact, which leads to positive feelings and well-being (George and Solomon, 2016). The seek for proximity in non-threatening situations can also occur, and it strengthens the child-caregiver bond (Julius et al., 2013). The caregiver also plays other roles in this relationship, such as educator and a playmate (Cassidy, 2016).

Ainsworth et al. (1978), using the well-known Stranger Situation Test paradigm (ASST), described three styles of child attachment, largely influenced by the caregiver behavior: secure, insecure avoidant, and insecure ambivalent; a fourth style, called disorganized, was introduced by Main and Solomon (1986). According to Cassidy's (2016) deep examination of Bowlby's theory, the systems involved in the child-caregiver attachment also encompass cognitive components such as memory, selective attention, and discriminant learning, among others. Repeated cognitive and affective experiences with the attachment figure form the so-called internal working models (Bowlby, 1969) that can influence the way individuals will form future relationships.

\section{ADULT AND FRIENDSHIP ATTACHMENT}

Hazan and Shaver (1987) stated that, as children grow up, the attachment system does not become inactive but it is, instead, co-opted and influences the development of new bonding in adulthood. During growth, people gradually shift attachment functions from parents to peers, such as a friend or romantic partner (Fraley, 2019). In these bi-directional relationships, each person can interchangeably play the care-seeking and the caregiving roles, depending on specific situations and individual needs.

Although early caregiving experiences continue to influence the attachment orientation in adulthood (Hazan and Shaver, 1987; Chopik et al., 2014), Fraley (2019) argues that this influence can be weaker than previously thought. When two adult individuals develop an affectionate attachment, both can offer and receive support in difficult moments, each one bearing their own earlier experiences, resulting in a dynamic process of adaptation to one another. This plasticity is important for the establishment and maintainance of new relationships (Fraley, 2019), but the comprehension of how attachment patterns change during lifetime remains a challenge.

Adulthood bonding in humans is not a matter of life or death, as it is in childhood (Fraley, 2019). It seems to be driven less by biological needs and more by interpersonal needs. A friendship arises from long-term relationships that present consistency, connectedness, good communication, seeking for, and offering support to each other with high levels of trust, self-disclosure, hope, and relationship satisfaction (Welch and Houser, 2010). Friends also engage in a mutual enjoyable physical contact (Feeney and Woodhouse, 2016; Zeifman and Hazan, 2016), although to a lesser degree than in the childcaregiver dyad. Berndt (2002) noted that a high quality of friendship is characterized by high level of positive features such as pro-social behaviors and is predictive of subjective well-being (Chopik, 2017). Although a friendship usually does not cause separation distress, most theorists describe it as an attachment bond.

Seyfarth and Cheney (2012) used the term friendship to describe enduring social bonds observed in many group-living mammals, suggesting that friendship improves survival, and reproductive fitness. According to them, friendship involves cooperative interactions that can be widely separated in time, depending on memory, and emotions associated with past interactions. Intraspecific friendship is more common in individuals that are genetically related, closer in age and rank; however, it is observed between unrelated individuals (Seyfarth and Cheney, 2012).

\section{DOG-DOG ATTACHMENT}

The study of attachment bonds in dogs has focused on their relationship with humans. The presence of an intraspecific attachment bond has instead received scant attention. Studies on separation from conspecifics (Pettijohn et al., 1977; Tuber et al., 1996; Walker et al., 2014) seem to point to a difference in the nature of the social relationships dogs establish with humans and those they establish with conspecifics. Recent studies have also highlighted similarities in the relationship (not attachment) established with humans and with other dogs (Cimarelli et al., 2019).

As for intraspecific attachment, preliminary data suggest that an attachment behavioral system exists in the puppy-mother relationship (Prato-Previde et al., 2009). Although separation stress was observed in an intraspecific version of the ASST (Mariti et al., 2018), Mariti et al. (2014) did not find evidence of an attachment system in intraspecific relationships between adult dogs. In case puppies and mother keep living together in adulthood, the bond between them presents some characteristics of an attachment, more than the bond between two unrelated, co-habitant adult dogs (Mariti et al., 2017).

The use of ASST with couples of co-habitant adult dogs showed that the presence of a human stranger had a stronger ameliorative effect when compared to the presence of an older female dog living in the same household. Nonetheless, the ameliorative effect was almost identical when the stranger was compared to the canine mother (Mariti et al., 2017). The bond between adult dogs does not seem to fit all the characteristics of an attachment bond as intended in a child-caregiver or in a dog-human bond (Mariti et al., 2013). However, results should not be regarded as conclusive, considering the small number of studies on this topic and the peculiar appeal that human beings have to dogs. Such bond might be better investigated using different tools.

It must also be noticed that many factors may impact the kind of relationship dogs establish with conspecifics and the behavior dogs display in the ASST test. For instance, early weaning (Mogi et al., 2011), early separation from littermates (Pierantoni et al., 2011), the amount of maternal care received (Guardini et al., 
2017), as well as disruption of the bond with tutors (PratoPrevide and Valsecchi, 2007), are all factors known to affect the development of dogs' social and emotional behaviors. At the same time, the age of the dog might influence the display of attachment-related behaviors both in intraspecific (Carlone et al., 2014) and interspecific tests (Mongillo et al., 2013).

\section{DOG-TUTOR ATTACHMENT: A CHILD-CAREGIVER OR A FRIENDSHIP ATTACHMENT?}

Dog-human dyads can establish many different kinds of relationship and bonding (Payne et al., 2015); however, when specifically studying attachment bonds, authors refer to the childcaregiver one (Rehn and Keeling, 2016).

If we compare the dog-tutor bond to the child-caregiver attachment, what would be the role, and the weight, of the attachment system, and caregiving system that the tutor and the dog carry in this relationship? Many questions arise at this point and not all can be easily answered.

The child-caregiver approach explains a good part of the dogtutor relationship. Most decisions in the dog's life are made by the tutor, who plays the role of caregiver and provider of the dog's needs, including security. The ASST adapted to study the bond developed by the dog toward the tutor has been widely used and has repeatedly shown that dogs behave similarly to children in a stressful situation, seeking for the proximity of their tutors, preferring them to an unfamiliar person and exploring their surroundings more when tutors are present (e.g., see Topál et al., 1998; Palmer and Custance, 2008; Mongillo et al., 2013; Mariti et al., 2018; Carlone et al., 2019). Both the secure base (Mariti et al., 2013) and the safe haven effect (Gácsi et al., 2013) have been observed in the dog-tutor bond. Preliminary data also suggest that dogs tested in the ASST with their tutors present similar attachment styles as children (Solomon et al., 2019).

However, the dog-tutor relationship is a more complex phenomenon. For almost their lifetime together tutor and dog are adult individuals, from different species. The well-distinguished roles of the child and caregiver are not fixed in the dogtutor attachment. The relationship is less asymmetrical and more reciprocal than the child-caregiver bond. Dogs can also represent an attachment figure for people. Separation from the dog can trigger anxiety and anguish in the tutor (Zilcha-Mano et al., 2011), while the close presence of the dog makes the tutor more confident in thinking about future goals and how to accomplish them (Zilcha-Mano et al., 2012). Sometimes the dog represents comfort and emotional support to the tutor in moments of distress (Zasloff, 1996; Dwyer et al., 2006). In this sense dogs also play a role like a secure base and safe haven for the tutor.

We can hypothesize that dogs, as humans, can carry both attachment and caregiving systems into their adult lifetime. Based on the literature, we suggest that dogs may have: an attachment system, activated by emotional stressful situations and deactivated by the proximity/contact with their tutor; and a caregiving system, activated by the dog's perception of distress or danger surrounding the tutor and deactivated by the tutor's signals of recovered well-being. Skills such as emotion recognition (Albuquerque et al., 2016) and empathy (Custance and Mayer, 2012) toward humans have already been recognized in dogs. This empathic ability motivates prosocial and helping behaviors, as demonstrated in studies in which dogs rescued their tutors from a distressful situation (Sanford et al., 2018; Carballo et al., 2020; Van Bourg et al., 2020). These evidences reinforce the plausibility of the hypothesis that dogs can also carry a type of caregiving system, but more studies are needed to better investigate the role of caregiver in dogs.

On one hand, the friendship attachment theory seems to partially explain the dynamic process of adaptation of dog and tutor to one another, combining two strategies of offering and receiving support in difficult moments. From the human's point of view, a relationship with a dog appears to be driven by interpersonal needs, a search for a long-term relationships with consistency, connectedness and closeness (Kurdek, 2009), which also resembles what a friendship offers for people (Welch and Houser, 2010; Chopik, 2017). From the adult dog's perspective, the relationship with a human is not a matter of life or death, stray dogs, for example, survive. Then, dogs also have different motivations than children to develop an attachment to their tutors, and they have a notably appeal for relationships with humans (Lazzaroni et al., 2020).

On the other hand, the child-caregiver attachment theory remains important in explaining the frequent and intense body contact between tutor and dog. The skin-to-skin contact triggers oxytocin release (see Julius et al., 2013, for a deeper discussion), the increase of which has also been demonstrated in affiliative interactions between dogs and humans (Nagasawa et al., 2009, 2015; Handlin et al., 2011, 2012). This important aspect makes the interspecific bond similar to the child-caregiver attachment.

Although along this opinion piece we focused our analyses in the relationship between an adult dog and an adult tutor, it must be noticed that, when they are puppies, dogs have the opportunity to establish a young-caregiver attachment bond, which adds even more complexity to this discussion, since it can involve a mother and/or a human caregiver (Prato-Previde et al., 2009; Mariti et al., 2020).

For social species, natural selection would have favored individuals who are motivated to form long-term bonds, not exclusively with kin (Seyfarth and Cheney, 2012). The dog-tutor attachment represents a strong, long-term bond that goes beyond the species. Whether the dog is the tutor's child or the best friend, or both, this attachment bond may be adaptative for both species and thus requires further research to be better understood.

\section{CONCLUSIONS}

Several arguments support that the dog-tutor relationship comprises characteristics of different types of attachment bonds. We suggest that child-caregiver attachment is not enough to characterize this interspecific bond and that a more integrative theory, that combines child-caregiver and friendship attachment should be considered. For example, while investigating dog-tutor 
attachment, questionnaires could include characteristics usually present in adult friendship; and behavioral tests could include situations aimed at triggering the caregiving system in dogs, to analyze how dogs offer support for their tutors. By suggesting that dog-tutor attachment integrates characteristics of different kinds of attachment bonds, we hope to provide a better picture of a bond that is one of the most important interspecific affectionate relationships for both species, and which appears to be much more complex than previously considered, a complexity that can be attribute to both parties.

\section{REFERENCES}

Ainsworth, M. D. S., Blehar, M. C., Waters, E., and Wall, S. (1978). Patterns of Attachment: A Psychological Study of the Strange Situation. Hillsdale, NJ: Lawrence Erlbaum Associates.

Albuquerque, N., Guo, K., Wilkinson, A., Savalli, C., Otta, E., and Mills, D. (2016). Dogs recognize dog and human emotions. Biol. Lett. 12:20150883. doi: $10.1098 / \mathrm{rsbl} .2015 .0883$

Berndt, T. J. (2002). Friendship quality and social development. Curr. Dir. Psychol. Sci. 11, 7-10. doi: 10.1111/1467-8721.00157

Bowlby, J. (1969). Attachment and Loss: Vol 1. Attachment. New York, NY:Basic Books.

Carballo, F., Dzik, V., Freidin, E., Damián, J. P., and Casanave, E. B., and Bentosela, M. (2020). Do dogs rescue their owners from a stressful situation? A behavioral and physiological assessment. Animal Cognition 23, 389-403. doi: 10.1007/s10071-019-01343-5

Carlone, B., Ricci, E., Votta, E., Gazzano, A., Guardini, G., and Mariti, C. (2014). Intraspecific attachment in domestic dogs (Canis familiaris): does it differ from young adults to adults? J. Vet. Behav. 9, e1-e19. doi: 10.1016/j.jveb.2014.09.014

Carlone, B., Sighieri, C., Gazzano, A., and Mariti, C. (2019). The dog (Canis familiaris) as part of the family: a pilot study on the analysis of dog bond to all the owners. Dog Behav. 5, 1-14. doi: 10.4454/db.v5i1.90

Cassidy, J. (2016). “The nature of child's ties," in: Handbook of Attachment - Theory, Research and Clinical Applications. 3rd edn. eds J. Cassidy and P. R Shaver (New York, NY: Guilford press), 3-24.

Chopik, W. J. (2017). Associations among relational values, support, health, and well-being across the adult lifespan. Pers. Relationships 24, 408-422. doi: $10.1111 /$ pere. 12187

Chopik, W. J., Moors, A. C., and Edelstein, R. S. (2014). Maternal nurturance predicts decreases in attachment avoidance in emerging adulthood. J. Res. Personal. 53, 47-53. doi: 10.1016/j.jrp.2014.08.004

Cimarelli, G., Marshall-Pescini, S., Range, F., and Virányi, Z. (2019). Pet dogs' relationships vary rather individually than according to partner's species. Sci. Rep. 9:3437. doi: 10.1038/s41598-019-40164-x

Custance, D., and Mayer, J. (2012). Empathic-like responding by domestic dogs (Canis familiaris) to distress in humans: an exploratory study. Anim. Cogn. 15, 851-859. doi: 10.1007/s10071-012-0510-1

Dwyer, F., Bennett, P. C., and Coleman, G. J. (2006). Development of the Monash Dog Owner Relationship Scale (MDORS). Anthrozoos 19, 243-256. doi: 10.2752/089279306785415592

Feeney, B. C., and Woodhouse, S. S. (2016). "Caregiving," in Handbook of Attachment - Theory, Research and Clinical Applications. 3rd edn. eds J. Cassidy and P. R. Shaver (New York, NY: Guilford press), 827-851.

Fraley, R. C. (2019). Attachment in adulthood: recent developments, emerging debates and future directions. Annu. Rev. Psychol. 70, 401-422. doi: 10.1146/annurev-psych-010418-102813

Gácsi, M., Maros, K., Sernkvist, S., Farag,ó, T., and Miklósi, Á. (2013). Human analogue safe haven effect of the owner: behavioural and heart rate response to stressful social stimuli in dogs. PLoS ONE 8:e58475. doi: 10.1371/journal.pone.0058475

George, C., and Solomon, J. (2016). "The measure of attachment security and related constructs in infancy and early childhood," in Handbook of Attachment

\section{AUTHOR CONTRIBUTIONS}

CS and CM equally contributed to this opinion manuscript. Both authors reviewed and gave final approval for publication.

\section{ACKNOWLEDGMENTS}

We thank Giacomo Riggio and Silvana Buzato for helpful comments on a draft of the manuscript, and we also thank Sophia Avramides for her help with the English.

- Theory, Research and Clinical Applications. 3rd edn. eds J. Cassidy and P. R. Shaver (New York, NY: Guilford press), 366-398.

Guardini, G., Bowen, J., Mariti, C., Fatjò, J., Sighieri, C., and Gazzano, A. (2017). Influence of maternal care on behavioural development of domestic dogs (Canis Familiaris) living in a home environment. Animals 7:E93. doi: $10.3390 /$ ani7120093

Handlin, L., Hydbring-Sandberg, E., Nilsson, A., Ejdeback, M., Jansson, A., and Uvnas-Moberg, K. (2011). Short-term interaction between dogs and their owners: effects on oxitocin, cordtisol, insulin and heart rate - an exploratory study. Anthrozoos 24, 301-315. doi: 10.2752/175303711X13045914865385

Handlin, L., Nilsson, A., Ejdebäck, M., Hydbring-Sandberg, E., and UvnäsMoberg, K. (2012). Associations between the psychological characteristics of the human-dog relationship and oxytocin and cortisol levels. Anthrozoos 25, 215-228. doi: 10.2752/175303712X13316289505468

Hazan, C., and Shaver, P. R. (1987). Romantic love conceptualized as an attachment process. J. Pers. Soc. Psychol. 52, 511-524. doi: 10.1037/0022-3514.52.3.511

Julius, H., Beetz, A., Kotrschal, K., Turner, D., and Uvnas-Moberg, K. (2013). Attachment to Pets. Cambridge: Hogrefe.

Kurdek, L. A. (2009). Pet dogs as attachment figures for adult owners. J. Fam Psychol. 23, 439-446. doi: 10.1037/a0014979

Lazzaroni, M., Range, F., Backes, J., Portele, K., Scheck, K., and MarshallPescini, S. (2020). The Effect of domestication and experience on the social interaction of dogs and wolves with a human companion. Front. Psychol. 11:785. doi: $10.3389 /$ fpsyg.2020.00785

Main, M., and Solomon, J. (1986). "Discovery of a new, insecuredisorganized/disoriented attachment pattern," in Affective Development in Infancy. eds M. Yogman and T. B. Brazelton (Norwood, NJ: Ablex), 95-124.

Mariti, C., Carlone, B., Ricci, E., Sighieri, C., and Gazzano, A. (2014). Intraspecific attachment in adult domestic dogs (Canis familiaris): preliminary results. Appl. Anim.Behav. Sci. 152, 64-72. doi: 10.1016/j.applanim.2013.12.002

Mariti, C., Carlone, B., Sighieri, C., Campera, M., and Gazzano, A. (2018). Dog behavior in the Ainsworth Strange Situation Test during separation from the owner and from the cohabitant dog. Dog Behav. 4, 1-8. doi: 10.4454/db.v4i1.76

Mariti, C., Carlone, B., Votta, E., Ricci, E., Sighieri, C., and Gazzano, A. (2017). Intraspecific relationships in adult domestic dogs (Canis familiaris) living in the same household: A comparison of the relationship with the mother and an unrelated older female dog. Appl. Anim.Behav. Sci. 194, 62-66. doi: 10.1016/j.applanim.2017.05.014

Mariti, C., Lenzini, L., Carlone, B., Zilocchi, M., Ogi, A., and Gazzano, A. (2020). Does attachment to man already exist in 2 months old normally raised dog puppies? A pilot study. Dog Behav. 1, 1-11. doi 10.4454/db.v6i1.96

Mariti, C., Ricci, E., Zilocchi, M., and Gazzano, A. (2013). Owners as a secure base for their dogs. Behaviour 150, 1275-1294. doi: 10.1163/1568539X-00003095

Mogi, K., Nagasawa, M., and Kikusui, T. (2011). Developmental consequences and biological significance of mother-infant bonding. Prog. Neuropsychopharmacol. Biol. Psychiatry 35, 1232-1241. doi: 10.1016/j.pnpbp.2010.08.024

Mongillo, P., Pitteri, E., Carnier, P., Gabai, G., Adamelli, S., and Marinelli, L. (2013). Does the attachment system towards owners change in aged dogs? Physiol. Behav. 120, 64-69. doi: 10.1016/j.physbeh.2013.07.011

Nagasawa, M., Mitsui, S., En, S., Ohtani, M., Sakuma, Y., Mogi, K., et al. (2015). Oxytocin-gaze positive loop and the coevolution of human-dog bonds. Science 348, 333-336. doi: 10.1126/science.1261022 
Nagasawa,., M., Kikusui, T., Onaka, T., and Ohta, M. (2009). Dog's gaze at its owner increases owner's urinary oxytocin during social interaction. Horm. Behav. 55, 434-441. doi: 10.1016/j.yhbeh.2008.12.002

Palmer, R., and Custance, D. (2008). A counterbalanced version of Ainsworth's Strange Situation Procedure reveals secure-base effects in dog-human relationships. Appl. Anim.Behav. Sci. 109, 306-319. doi: 10.1016/j.applanim.2007.04.002

Payne, E., Bennett, P. C., and McGreevy, P. D. (2015). Current perspectives on attachment and bonding in the dog-human dyad. Psychol. Res. Behav. Manag. 8, 71-79. doi: 10.2147/PRBM.S74972

Pettijohn, T. F., Wong, T. W., Ebert, P. D., and Scott, J. P. (1977). Alleviation of separation distress in 3 breeds of young dogs. Dev. Psychol. 10, 373-381. doi: $10.1002 /$ dev.420100413

Pierantoni, L., Albertini, M., and Pirrone, F. (2011). Prevalence of owner-reported behaviours in dogs separated from the litter at two different ages. Vet. Rec. 169:468. doi: 10.1136/vr.d4967

Prato-Previde, E., Ghirardelli, G., Marshall-Pescini, S., and Valsecchi, P. (2009). Intraspecific attachment in domestic puppies (Canis familiaris). J. Vet. Behav. 4, 89-90. doi: 10.1016/j.jveb.2008.10.002

Prato-Previde, E., and Valsecchi, P. (2007). Effect of abandonment on attachment behavior of adult pet dogs. J. Vet. Behav. 2, 87-88. doi: 10.1016/j.jveb.2007. 04.015

Rehn, T., and Keeling, L. J. (2016). Measuring dog-owner relationships: crossing boundaries between animal behaviour and human psychology. Appl. Anim.Behav. Sci. 183, 1-9. doi: 10.1016/j.applanim.2016.07.003

Sanford, E. M., Burt, E. R., and Meyers-Manor, J. E. (2018). Timmy's in the well: empathy and prosocial helping in dogs. Learn. Behav. 46, 374-386. doi: 10.3758/s13420-018-0332-3

Serpell, J. (2017). The Domestic Dog. Its Evolution, Behavior and Interactions With People. 2nd edn. Cambridge: Cambridge university press. doi: $10.1017 / 9781139161800$

Seyfarth, R. M., and Cheney, D. L. (2012). The evolutionary origins of friendship. Annu. Rev. Psychol. 63, 153-177. doi: 10.1146/annurev-psych-120710-100337

Solomon, J., Beetz, A., Schöberl, I., Gee, N., and Kotrschal, K. (2019). Attachment security in companion dogs: adaptation of Ainsworth's strange situation and classification procedures to dogs and their human caregivers. Attach. Hum. Dev. 21, 389-417. doi: 10.1080/14616734.2018.1517812

Topál, J., Miklósi, A., Dóka, A., and Csányi, V. (1998). Attachment behavior in dogs (Canis familiaris): a new application of Ainsworth's (1969) strange situation test. J. Comp. Psychol. 112, 219-229. doi: 10.1037/0735-7036.112.3.219
Tuber, D. S., Hennessy, M. B., Sanders, S., and Miller, J. A. (1996). Behavioral and glucocorticoid responses of adult domestic dogs (Canis familiaris) to companionship and social separation. J. Comp. Psychol. 110, 103-108. doi: 10.1037/0735-7036.110.1.103

Van Bourg, J., Patterson, J. E., and Wynne, C. D. L. (2020). Pet dogs (Canis lupus familiaris) release their trapped and distressed owners: Individual variation and evidence of emotional contagion. PLOS ONE 15:e0231742. doi: 10.1371/journal.pone.0231742

Walker, J. K., Waran, N. K., and Phillips, C. J. C. (2014). The effect of conspecific removal on the behaviour and physiology of pair-housed shelter dogs. Appl. Anim. Behav. Sc. 158, 46-65. doi: 10.1016/j.applanim.2014.06.010

Welch, R. D., and Houser, M. E. (2010). Extending the four-category model of human attachment: an interpersonal model of friendship attachment. J. Soc. Pers. Relat. 27, 351-366. doi: 10.1177/0265407509349632

Zasloff, R. L. (1996). Measuring attachment to companion animals: a $\operatorname{dog}$ is not a cat is not a bird. Appl. Anim.Behav. Sci. 47, 43-48. doi: 10.1016/0168-1591(95)01009-2

Zeifman, D. M., and Hazan, C. (2016). "Pair bonds as attachments: mounting evidence in support of Bowlby's hypothesis," in Handbook of Attachment Theory, Research and Clinical Applications. 3rd edn. eds J. Cassidy and P. R. Shaver. (New York, NY: Guilford press), 416-434.

Zilcha-Mano, S., Mikulincer, M., and Shaver, P. R. (2011). An attachment perspective on human-pet relationships: Conceptualization and assessment of pet attachment orientations. J. Res. Pers. 45, 345-357. doi: 10.1016/j.jrp.2011.0 4.001

Zilcha-Mano, S., Mikulincer, M., and Shaver, P. R. (2012). Pets as safe havens and secure bases: The moderating role of pet attachment orientations. J. Res. Pers. 46, 571-580. doi: 10.1016/j.jrp.2012.0 6.005

Conflict of Interest: The authors declare that the research was conducted in the absence of any commercial or financial relationships that could be construed as a potential conflict of interest.

Copyright (c) 2020 Savalli and Mariti. This is an open-access article distributed under the terms of the Creative Commons Attribution License (CC BY). The use, distribution or reproduction in other forums is permitted, provided the original author(s) and the copyright owner(s) are credited and that the original publication in this journal is cited, in accordance with accepted academic practice. No use, distribution or reproduction is permitted which does not comply with these terms. 